\title{
Collaboration Between Scientists and Teachers Using Twitter
}

\author{
Kayla Norville \\ North Carolina State University
}

\section{INTRODUCTION}

hen considering how you learned science when you were in school, do you remember participating
in authentic science or do you recall memorizing facts? Unfortunately, most of us may say the latter; however, there are changes currently occurring in science education that strive to reconstruct this trajectory. Science education reform has emphasized the partnership between teachers and scientists (Kim \& Herbert, 2011) in order to increase authentic scientific inquiry in the classroom. Authentic science has been shown to positively influence students' science identity, allow students to develop critical science skills, and increase student motivation (Chapman \& Feldman, 2017; Hellgren, 2017; Tarjan, de Nesnera, \& Hoffman, 2015). Therefore, the partnership between scientists and teachers to generate authentic science in the classroom has become increasingly crucial. One way to assist teachers to partner with scientists is through the social media platforms such as, Twitter. Educators have shown increasing interest in using Twitter as a source of professional development and collaboration with others (Xing \& Gao, 2018). Considering this, collaboration on Twitter can also play a role in the social capital of teachers. Social capital can be defined as the "relational resources embedded in the cross-cutting personal ties that are useful for the development of individuals in community social organizations" (Tsai \& Ghoshal, 1998, p. 404). However, there has been a lack of research that examines the impact of Twitter on teachers' social capital (Rhem \& Notten, 2016).

Twitter can provide quality professional development for teachers including the opportunity to collaborate with scientists (Shein \& Tsai, 2015). Citizen science, science conducted by regular people (McKenney, Flythe, Millis, Stalls, Urban, Dunn, \& Stevens, 2016) has been practiced at least since the 1700s (Raddick, Bracey, Carney, Gyuk, Borne, Wallin, \& Jacoby, 2009). In 2009, Raddick and colleagues suggested that citizen science be incorporated into K-12 classrooms. Citizen science allows students to participate in authentic scientific research. Students engaging in citizen science have the opportunity to collect data to send to scientists that could assist them in making new discoveries (Students Discover, 2015). For example, in the Students Discover "The Great Pumpkin Project," students can collect data, such as insect population and how plants change over time, from a local garden and send this data to scientists to assist them in discovering the relationships between insects, plants, and microbes. In return, students are able to learn about items such as plant-insect-microbe interactions and the importance of bees and plant pollination. Another example is the project entitled "Journey North"(journeynorth.org) in which students learn about migration patterns and seasonal changes by collecting data about hummingbirds, monarch butterflies, and other organisms. Students report sightings of these particular organisms, assisting scientists in making discoveries about seasons and migrations. There is evidence of these types of lessons being designed; however, there is less evidence of implementation in the classroom (Students Discover, 2015; SciStarter, 2017). It is possible that this is caused by a lack of communication among scientists involved in the projects and teachers in the classroom. 
To address the lack of communication among scientists and teachers, the social media platform, Twitter, could be a useful tool. Over the years, Twitter has become an informal learning space for teachers (Rehm \& Notten, 2016). Teachers use hashtags such as \#scichat to collaborate with each other, share resources, stay informed about current educational practices, and hold conversations with people and organizations from around the world. Personal learning networks have emerged from these conversations. Twitter could be an excellent platform for science teachers to connect with scientists in order to assist them with their research via citizen science, but are they using it? In this investigation, l explored the extent to which those involved in science teacher social networks are also involved in citizen science social networks. An overarching research question is "In what ways are K-12 science teachers involved in citizen science on Twitter?" The question was investigated with two sub-questions as follows:

a) What kind of overlaps exists between participants using science educator hashtags and citizen science hashtags?

b) What kind of overlaps exists between top influencers using science educator hashtags and citizen science hashtags?

Findings from this study could assist researchers in determining the next steps for Twitter usage among science teachers who are interested in collaborating with scientists and pursuing citizen science in their classrooms.

\section{METHODS}

Data were collected over a period of six weeks from five different hashtags on Twitter through NodeXL, an open-source template for Microsoft Excel which allows for the exploration of network graphs. Two of the hashtags are popular citizen science hashtags: \#citizenscience, \#citsci, and three of them are leading science teaching hashtags: \#scichat, \#scienceed, and \#scienceteacher. Many participants in the citizen science hashtag include scientists that are involved in research involving citizens. Many participants in the science teacher hashtags group are K-12 science teachers. Hashtags were selected based on personal experience as a science teacher who has implemented citizen science in the classroom, as well as, an in-depth internet search of the top science teacher and citizen science hashtags. One limitation of this study is that participants of each hashtag group cannot be confirmed as science teachers or scientists; however, this study assumes that the majority match these definitions. All vertices, which are participants using the particular hashtag, from the science teacher hashtags were collected into one spreadsheet, organized in alphabetical order, and then the duplicates were removed. The same process was conducted with both citizen science hashtags: \#citizenscience and \#citsci, in the same spreadsheet. In order to determine overlaps among vertices, duplicates were highlighted among both columns.

Graph metrics were calculated in NodeXL in order to determine top influencers for each hashtag. "Betweenness centrality," an indicator of a person's influence in the network, was one of the graph metrics calculated (Newman, 2001). This column was sorted from largest to smallest in order to determine the top influencers of each group. Influencers provide a "bridge" between different parts of the network. Without them, the network could fall apart. "Influencers may only represent a small percentage of an overall conversation; their role does ultimately shape how information spreads. Tapping into close communities makes content shareable, but topdown influence is essential for content to achieve truly viral speed and scale" (Parkin, 2014). NodeXL only allows for one week of data collection at a time; therefore, in this study, there were six different spreadsheets for each of the hashtags, totaling 30 spreadsheets in all. In order to determine top influencers over a period of 6 weeks, the top 10 influencers, determined by betweenness centrality, were documented. The top five vertices that appeared for the greatest amount of time were considered the top five influencers over the six-week period. 


\section{FINDINGS}

Research Sub-question 1: What kind of overlaps exist in participants in science educator hashtags and citizen science hashtags?

Overall, there were 8,311 unique vertices involved in the citizen science hashtags and 2,980 unique vertices involved in the science teacher hashtags. One-hundred and seventeen of the participants were involved in both sets of hashtags. Out of all the participants using the science teacher hashtags, approximately $4 \%$ of them were also involved in citizen science networks.

Research Sub-question 2: What kind of overlaps exist in top influencers in science educator hashtags and citizen science hashtags?

Top influencers are organized in Table 1. There were no overlaps among the citizen science top influencers and science teacher top influencers.

\section{Table 1}

Top influencers using Citizen Science Hashtags and Science Educator

\begin{tabular}{|c|c|c|c|c|}
\hline \#citizenscience & \#citsci & \#scichat & \#scienceed & \#scienceteacher \\
\hline ntxscied & coopsciscoop & garym & beth_heidemann & arludo \\
\hline coopsciscoop & siobhanleachman & tekieboard & go2science & sciteacheraward \\
\hline citscioz & citscioz & weareteachers & mtoy 2014 & wdlorg \\
\hline scistarter & inaturalist & ericcurts & roisinlaubs & teachinglc \\
\hline insectmigration & crowdandcloudtv & hatterchatter & sciencemarchpr & spanglerscience \\
\hline
\end{tabular}

\section{DISCUSSION AND IMPLICATIONS}

This study examined the involvement of users of the science teacher hashtags in the use of citizen science hashtags and revealed that only $4 \%$ of those using science teacher hashtags were using citizen science hashtags as well. The findings of this study could potentially add understandings to social network and science education literature. First, it suggests that there may be a disconnect between science teachers and the rest of the citizen science community, at least in the "world of" Twitter. Connecting science teachers with members of the citizen science community would greatly contribute to citizen science as well as science teaching and learning.

Understanding whether or not there is a disconnect between scientists and science teachers could lead to initiatives that would bring more authentic science into the classroom.

Second, there were no overlaps among the top influencers in each social network. If scientists who are interested in citizen science for youth become involved in science educator hashtags to the extent that they become a top influencer, science classrooms could be impacted in a positive way. Conversations on Twitter can contribute to the formation of social capital for both teachers and scientists which this could be also benefit the educational and scientific communities (Rehm \& Notten, 2016). 
In order to facilitate greater collaboration between scientists and science teachers on Twitter, future studies could focus on intervention. A possible next step would be to connect the top influencers in each category in order to brainstorm ways in which science teachers and scientists could collaborate.

\section{REFERENCES}

Chapman, A., \& Feldman, A. (2017). Cultivation of science identity through authentic science in an urban high school classroom. Cultural Studies of Science Education, 12(2), 469-491.

Hellgren, J. (2017). Motivating students with authentic science experiences: changes in motivation for school science. Research in Science and Technological Education, 35(4), 409.

Kim, H. J., \& Herbert, B. (2011). Inquiry Resources Collection as a Boundary Object Supporting Meaningful Collaboration in a Wiki-Based Scientist-Teacher Community. Journal of Science Education and Technology, 21(4), 504-512.

Mahoney, B. (2013). Hashtags, Mentions, and Following: Creating a PLN with Twitter. Middle Ground, 16(4), 22-23.

McHeyzer-Williams, L. J., \& McHeyzer-Williams, M. (2016). Our Year on Twitter: Science in \#SocialMedia. Trends In Immunology, 37(4), 290-295.

McKenney, E., Flythe, T., Millis, C., Stalls, J., Urban, J., Dunn, R., \& Stevens, J. (2016). Symbiosis in the Soil: Citizen Microbiology in Middle School and High School Classrooms. Journal of Microbiology and Biology Education, 17(1), 60-62.

Newman, M. (2005). A measure of betweenness centrality based on random walks. Social Networks, 27(1), 39-54.

Parkin, R. (2014, April 6). Identifying Influencers with Social Network Analysis. Retrieved from https://www.pulsarplatform.com/blog/2014/identifying-influencers-with-social-network-analysis/

Raddick, J., Bracey, G., Carney, K., Gyuk, G., Borne, K., Wallin, J., \& Jacoby, S. (2009). Citizen Science: Status and Research Directions for the Coming Decade. The Astronomy and Astrophysics Decadal Survey, Position Papers, 46.

Rehm, M., \& Notten, A. (2016). Twitter as an informal learning space for teachers!? The role of social capital in Twitter conversations among teachers. Science Direct, 60, 215-223.

Shein, P. P., \& Tsai, C.-Y. (2015). Inquiry Resources Collection as a Boundary Object Supporting Meaningful Collaboration in a Wiki-Based Scientist-Teacher Community Impact of a Scientist-Teacher Collaborative Model on Students, Teachers, and Scientists. International Journal of Science Education, 37(13), 21472169.

Scistarter: Science we can do together. (2017). Retrieved from https://scistarter.com/

Students Discover. (2015). Retrieved from http://studentsdiscover.org/research/microbes/

Tarjan, L. M., de Nesnera, K., \& Hoffman, R. (2015). Authentic science investigation in the classroom: Tools for creating original, testable questions and graphical hypotheses. Science Scope, 39(4), 42-48.

Tsai, W., \& Ghoshal, S. (1998). Social Capital and Value Creation: The Role of Intrafirm Networks. The Academy of Management Journal, 41(4), 464-476. 
Xing, W., \& Gao, F. (2018). Exploring the relationship between online discourse and commitment in Twitter professional learning communities. Computers and Education, 126, 388-398.

\section{About the Author}

Kayla Norville, Science Education Ph.D. student at North Carolina State University, and 2014-15 Kenan Fellow 